Gut, 1964, 5, 546

\title{
Gastric mucosal structure and function after vagotomy
}

\author{
A. G. MELROSE, R. I. RUSSELL, AND A. DICK \\ From the Gastrointestinal Clinic and Department of Pathology, \\ Southern General Hospital, Glasgow
}

EDITORIAL SYNOPSIS No evidence of parietal cell atrophy has been found following vagotomy. These studies have also shown that the mechanism by which glucagon inhibits gastric secretion is independent of vagal innervation.

Vagotomy, combined with a drainage procedure, has become increasingly popular in the surgical treatment of chronic duodenal ulcer. After operation the nervous phase of gastric secretion is abolished and the maximum secretory response to histamine, varying in degree from $70 \%$ (Falconer, 1959) to $80 \%$, (Gillespie, Clark, Kay, and Tankel, 1960) is reduced. The role of the vagus nerves in gastric secretion is known to be a complex one, and the mechanism responsible for the marked reduction in gastric secretory capacity following vagotomy has been the subject of much recent investigation. It is known that the responsiveness of the parietal cells to secretory stimuli depends upon intact vagal innervation, and there is evidence (Payne and Kay, 1962) that withdrawal of the permissive role of the vagus following section of the vagus nerve is an important factor in reducing acid secretory capacity. It is also possible that the continued and prolonged suppression of acid secretion following section of the vagal pathways could result from parietal cell hypoplasia and atrophy, perhaps as a manifestation of withdrawal of 'trophic' influence. No other factors which might contribute to the observed reduction in gastric acid output have been clearly identified. The associated drainage operation plays no part in producing the fall in acid secretion, since neither gastroenterostomy alone (Tankel, Gillespie, Clark, Kay, and McArthur, 1960) nor pyloroplasty alone (Gelb, Baronofsky, and Janowitz, 1961) significantly alter the maximal acid response. Thomson and Vane (1953) have shown that the secretory response to histamine can be correlated with gastric mucosal blood flow, but evidence is lacking that vagal section maintains impairment of mucosal vascular supply.

Most investigations on vagotomized patients in the past have dealt with changes in gastric secretion. In the present study the gastric mucosa has been examined in a group of subjects at intervals of up to 10 years following vagotomy, and with a few exceptions the morphological appearances have been correlated with gastric secretory capacity as determined by a modified insulin test meal procedure.

\section{METHODS AND RESULTS}

Forty-six patients who had undergone vagotomy one to 10 years previously were studied. The associated drainage procedure had been gastrojejunostomy in 34 and pyloroplasty in 12. Preliminary clinical assessment was followed by a full blood examination which included a platelet count, since a clotting defect would have rendered suction biopsy hazardous. Gastric mucosal biopsy was then performed using Wood's flexible gastric biopsy tube. In order to reduce sampling error (Bockus, 1963) whenever possible more than one biopsy was taken from each case, and in the group as a whole the average number of biopsy specimens per patient was two. Each section was stained with haematoxylin and eosin, a trichrome stain, and a mucin stain. The gastric biopsies were examined and reported by one of us (A.D.) who, at the time of observation, was totally unaware of the clinical history. If two or more specimens were obtained it was known that they came from the same patient. Three stains were performed on every biopsy and at least two sections stained by each method; on the average six slides per biopsy were examined. In order to minimize the observer error the slides were subsequently reviewed on two subsequent occasions before analysis was undertaken. According to their histological features the specimens were classified, using the criteria of Bock, Richards, and Witts (1963), into normal, superficial gastritis, atrophic gastritis, and gastric atrophy.

In 39 of the 46 patients a modified insulin test meal was carried out as follows. With the patient in the fasting state the stomach was emptied of resting juice using 
TABLE I

CLASSIFICATION OF GASTRIC MUCOSAL CHANGES

\begin{tabular}{|c|c|c|c|c|c|}
\hline & Normal & Superficial Gastritis & Atrophic Gastritis & Gastric Atrophy & Total \\
\hline $\begin{array}{l}\text { Present series (1964) } \\
\text { Series of Joske et al. (1955) }\end{array}$ & $\begin{array}{r}4 \\
167\end{array}$ & $\begin{array}{r}22 \\
431\end{array}$ & $\begin{array}{r}20 \\
346\end{array}$ & $\begin{array}{r}0 \\
56\end{array}$ & $\begin{array}{r}46 \\
1,000\end{array}$ \\
\hline
\end{tabular}

intermittent followed by continuous suction. When by careful positioning of the gastric tube it was found that this had been accomplished, gastric juice was collected for 15 minutes. Soluble insulin, 11 units, was then given intravenously and gastric juice collected during the ensuing 60 minutes was discarded. Juice obtained during the 60-75 minute period after insulin was collected and the hypoglycaemic phase was then terminated by giving glucagon, $2 \mathrm{mg}$., intravenously. The specimens of gastric juice collected before and after insulin injection were titrated for free acid using N/10 NaOH and Töpfer's solution as indicator. Blood sugar was determined before insulin injection and 60 minutes later; in every case it was found that insulin had reduced the blood sugar by at least $50 \%$ compared with the pre-insulin level, and the second estimation did not exceed $50 \mathrm{mg}$. per $100 \mathrm{ml}$. in any patient.

The dose of 11 units of soluble insulin used in this investigation was chosen following the observation of Stempien (1962) that it will achieve the desired $50 \%$ reduction in blood sugar for the purpose of an insulin test meal. Scrutiny of Stempien's data also suggested to us that there was little variation in free acid secretion between the first 15-minute period and any other similar period in most patients during the second post-insulin hour. Gastric juice was therefore collected as described, and there was the additional advantage that patients had to endure the sometimes unpleasant symptoms of hypoglycaemia for a shorter period than is usual when the conventional two-hour test is performed.

The results of the investigation are shown in Tables I-V. Of the 46 patients studied only four had a normal mucosa, the remainder showing superficial or atrophic gastritis. No patient was found to have gastric atrophy.

\section{TABLE II}

DURATION SINCE OPERATION RELATED TO GASTRIC MUCOSAL CHANGES

\begin{tabular}{lccc} 
Years & Normal & Superficial Gastritis & Atrophic Gastritis \\
\hline $0-2$ & 1 & 9 & 9 \\
$2-4$ & 2 & 7 & 5 \\
$4+$ & 1 & 6 & 6
\end{tabular}

TABLE III

\begin{tabular}{lrc} 
ACID OUTPUT DURING MODIFIED INSULIN TEST \\
MEAL RELATIVE TO TIME SINCE OPERATION \\
Years & $\begin{array}{c}\text { Mean 15-min. Output in } \\
\text { mEq. HCl. }\end{array}$ \\
\hline 1 & 12 & 1.5 \\
2 & 5 & 2.4 \\
3 & 6 & 1.1 \\
4 & 4 & 1.9 \\
5 & 12 & 1.6
\end{tabular}

TABLEIV

ACID OUTPUT DURING INSULIN TEST MEAL RELATED TO GASTRIC MUCOSAL CHANGES

Gastric Histology Mean 15-min. Output in $\mathrm{mEq} . \mathrm{HCl}$.

\begin{tabular}{ll}
\hline Normal & $3 \cdot 7$ \\
Superficial gastritis & $2 \cdot 2$ \\
Atrophic gastritis & $0 \cdot 95$
\end{tabular}

TABLE V

EFFECT OF AGE ON GASTRIC MUCOSAL CHANGES

\begin{tabular}{lccc}
$\begin{array}{l}\text { Age in } \\
\text { Years }\end{array}$ & Normal & Superficial Gastritis & Atrophic Gastritis \\
\hline $20-40$ & 3 & 9 & 4 \\
$41+$ & 1 & 13 & 16
\end{tabular}

DISCUSSION

The incidence of histological gastritis may appear high in this series, yet it should be noted that normal gastric mucosa is found in less than $50 \%$ of persons above the age of 40 (Joske, Finckh, and Wood, 1955). Further, peptic ulcer is itself associated with gastritis; 256 partial gastrectomy specimens removed in the surgical treatment of duodenal ulcer were examined by Magnus (1952) who reported that chronic gastritis was present in all cases. It is also established that chronic gastritis is somewhat common in the stomach after operation. Lees and Grandjean (1958) took biopsy samples from 33 asymptomatic patients from one to five years after the operation of partial gastrectomy and noted gastritis in two-thirds of cases. In order to verify that the distribution of mucosal appearances observed in the present study was due solely to vagotomy, comparison with a second series of patients who had had gastroenterostomy alone would have been of interest. This was not possible as the latter operation is now rarely performed. Nor would a prospective study, in which the gastric mucosa was examined before and after vagotomy, have been likely to prove rewarding. Gastric mucosal atrophy and duodenal ulcer are mutually exclusive disorders, and in a similar fashion, severe atrophic gastritis with its associated marked reduction in acid output (Wood, Doig, Motterham, Weiden, and Moore, 1949) would tend to safeguard the patient against the possibility of developing duodenal ulcer in the first instance. Few reports are available in which gastric biopsies from healthy persons have 
been obtained and classified according to histological pattern, but one of the most comprehensive is that of Joske et al. (1955). Their series is not strictly comparable with the present one because an unspecified number of patients had alimentary or other disorders. The pathologist has to make a diagnosis on a few fragments of gastric mucosa, and the crucial point is whether we are entitled to assume that the biopsy material is representative of the state of the gastric mucosa as a whole. This assumption is justified in view of the observations of Williams, Edwards, Lewis, and Coghill (1957), who noted agreement in approximately $90 \%$ of specimens taken at the same time irrespective of the site of the various samples. When the two series are compared (Table I) it is evident that there is no significant difference in the distribution of patients in the various categories.

Should vagal section lead to progressive atrophy of parietal cells it would also be reasonable to expect a progressive increase in the incidence of atrophic gastritis with increasing time since operation. It is evident that no such tendency exists (Table II). Further, gastric secretory capacity in response to insulin stimulation shows no tendency to diminish with increasing time after operation (Table III), nor in these patients does acid output show a tendency to rise towards normal levels for up to 10 years after vagotomy. Bock et al. (1963) have shown that the amount of acid secreted by the stomach on augmented histamine stimulation is closely correlated with the histological appearance of the gastric mucosa; in general, the more abnormal the mucosa, the less acid it can secrete. Additional confirmatory evidence is supplied in the present study (Table IV). Atrophic gastritis may be a manifestation of the ageing process and would then occur irrespective of vagotomy. Classification of the biopsies according to the ages of the patients tends to support this view. Atrophic gastritis is noted to be much more frequent after the age of $\mathbf{4 0}$ than before that age (Table V). Analysis of the results in the present investigation does not support the hypothesis that parietal cell hypoplasia or atrophy occurs after vagotomy, or that the observed reduction in gastric acid output can be attributed to this cause.

The modified insulin test meal procedure used in this investigation was not devised primarily as a test for the completeness of vagotomy. When the assumption is made (vide supra) that the acid output in the period 60-75 minutes after insulin injection is representative of the gastric secretory response during the second post-insulin hour, the data on the 39 patients can be analysed for this purpose. Using the criteria of Bachrach (1962), 26 vagotomies were complete or adequate and 13 incomplete. By the standards defined by Stempien (1962), 25 were complete and 14 incomplete. It has long been recognized that the Hollander (1946) test meal using insulin for completeness of vagotomy shows approximately a $40 \%$ incidence of incomplete operation, and our data show little divergence from this estimate. Ross (1962) has carried out both augmented histamine and insulin test meals on a group of patients after vagotomy with results which suggest that twothirds of apparently incomplete vagotomies are in fact complete; late secretory responses could occur despite adequate vagal section. It is apparent that the insulin test meal as conventionally performed requires reassessment.

Glucagon not only has a hyperglycaemic effect when given intravenously but also inhibits gastric acid secretion (Melrose, 1960). In the present series of experiments, whenever insulin had succeeded in producing an acid secretory response, collection of gastric juice was continued for a further 15 minutes after glucagon had been given. In every case a fall in acid output was observed. Lin and Alphin (1958) report that the inhibition of gastric secretion by glucagon in the dog is independent of vagal innervation, and our observations in human subjects support this view.

\section{SUMMARY}

After vagotomy there is a marked reduction in the gastric secretory capacity of the stomach which, it has been suggested, could be due to parietal cell hypoplasia or atrophy. In order to test this hypothesis, gastric mucosal biopsy was carried out in 46 patients who between one and 10 years previously had undergone vagotomy combined with a drainage operation. Thirty-nine of these patients also had a modified insulin test meal procedure. Frank gastric atrophy was not found in any patient, and neither the histological changes in the gastric mucosa nor the gastric secretory patterns yielded definite evidence that parietal cell atrophy occurs as a sequel to vagotomy. Increasing degrees of mucosal abnormality were noted to be associated with diminishing capacity to secrete acid.

Hypoglycaemia induced during the insulin test meal in these patients was terminated by the intravenous injection of glucagon. It was observed that a fall in acid output invariably followed, and it is pointed out that the mechanism by which glucagon inhibits gastric secretion can be regarded as independent of vagal innervation.

We are indebted to Dr. L. D. W. Scott and Mr. R. B. Wright for advice, and also to the latter for permission to study his patients. 


\section{REFERENCES}

Bachrach, W. H. (1962). Laboratory criteria for the completeness of vagotomy. Amer. J. dig. Dis., 7, 1071-1085.

Bock, O. A. A., Richards, W. C. D., and Witts, L. T. (1963). The relationship between acid secretion after augmented histamine stimulation and the histology of the gastric mucosa. Gut, 4 112-114.

Bockus, H. L. (1963). Gastroenterology, vol. I, p. 384. 2nd ed. W. B. Saunders \& Co., Philadelphia and London.

Falconer, C. W. A. (1959). Discussion on the surgical management of chronic duodenal ulcer. Proc. roy. Soc. Med., 52, 840-842.

Gelb, A. M., Baronofsky, I. D., and Janowitz, H. D. (1961). The effect of vagotomy and pyloroplasty on the maximal acid response to histamine. Gut, 2, 240-245.

Gillespie, I. E., Clark, D. H., Kay, A. W., and Tankel, H. I. (1960) Effect of antrectomy, vagotomy with gastrojejunostomy, and antrectomy with vagotomy on the spontaneous and maximal gastric acid output in man. Gastroenterology, 38, 361-367.

Hollander, F. (1946). The insulin test for the presence of intact nerve fibres after vagal operations for peptic ulcer. Ibid., 7, 607-614.

Joske, R. A., Finckh, E. S., and Wood, I. J. (1955). Gastric biopsy: a study of 1,000 consecutive successful gastric biopsies. Quart. J. Med., 24, 269-294.

Lees, F., and Grandjean, L. C. (1958). The gastric and jejunal mucosae in healthy patients with partial gastrectomy. Arch. intern. Med., 101, 943-951.
Lin, T. M., and Alphin, R. S. (1958). Inhibition of gastric secretion by glucagon and glucose in the dog. Fed. Proc., 17, 97.

Magnus, H. A. (1952). in Modern Trends in Gastroenterology. 1st Series, pp. 323-351, edited by F. Avery Jones. Butterworth, London.

Melrose, A. G. (1960). Effect of glucagon on gastric secretion in man. Gut, 1, 142-145.

Payne, R. A., and Kay, A. W. (1962). The effect of vagotomy on the maximal acid secretory response to histamine in man. Clin. Sci. 22, 373-382.

Ross, B. (1962). Interpretation of positive responses to the insulin test. Brit. J. Surg., 50, 95.

Stempien, S. J. (1962). Insulin gastric analysis: technic and interpretations. Amer. J. dig. Dis., 7, 138-152.

Tankel, H. I., Gillespie, I. E., Clark, D. H., Kay, A. W., and McArthur, J. (1960). A clinical and statistical study of the effect of gastrojejunostomy on human gastric secretion. Gut, 1, 223-229.

Thomson, J. E., and Vane, J. R. (1953). Gastric secretion induced by histamine and its relationship to the rate of blood flow. J. Physiol. (Lond.), 121, 433-444.

Williams, A. W., Edwards, F. C., Lewis, T. H. C., and Coghill, N. F (1957). Investigation on non-ulcer dyspepsia by gastric biopsy. Brit. med. J., 11 372-377.

Wood, I. J., Doig, R. K., Motterham, R., Weiden, S., and Moore, A (1949). The relationship between the secretions of the gastric mucosa and its morphology as shown by biopsy specimens. Gastroenterology, 12, 949-958. 